\title{
LAS TRANSFORMACIONES DEL OFICIO
}

\author{
Enrique Florescano
}

Tistoria Mexicana aparece en el año 1951. Una década más 1 tarde, en 1961, Robert A. Potash, el distinguido historiador estadounidense, escribió: es "la revista más importante de entre las consagradas a la historia de México en este siglo". Fundada por don Daniel Cosío Villegas, se propuso ser "una revista académica seria, estable, sin prejuicios o banderías, que acogiera los trabajos sobre historia mexicana de mexicanos y extranjeros".

Desde su primer número hasta 2021, cuando celebrará 70 años de vida, ha cumplido su propósito original. Sigue siendo fiel a su compromiso de presentarse a sus lectores cuatro veces al año, sin interrupciones. Cubre todas las épocas del desarrollo histórico del país y sus páginas reflejan las tendencias mayores de la investigación histórica de mexicanos y extranjeros.

A los artículos de sus colaboradores ha agregado secciones muy útiles: reseñas de libros, noticias de archivos, informes sobre congresos, discusiones sobre métodos y formas de historiar, etc. Así se convirtió en herramienta indispensable para conocer las aportaciones, las corrientes de investigación, los debates y las ideas de los historiadores. 
En sus páginas se han dado cita las variadas formas de comprender, explicar, criticar y debatir las obras del historiador. De este modo Historia Mexicana contribuyó a la profesionalización del quehacer historiográfico y es hoy consulta obligada para dar cuenta del desarrollo del pensamiento histórico en el país.

Otro rasgo importante de Historia Mexicana es su estabilidad y capacidad de cambio al compás de las transformaciones del oficio. Ambas se explican por su pertenencia a El Colegio de México, institución académica que la patrocina y cuida su continuidad profesional, al mismo tiempo que promueve el cambio de su dirección y del consejo editorial. Cada determinado tiempo hay relevo en la dirección de la revista o se incluyen nuevos miembros en su Consejo. Esto y los cambios generacionales han favorecido su constante renovación.

Tuve la fortuna de dirigir Historia Mexicana de enero de 1971 a diciembre de 1973. Con el acuerdo del Consejo Editorial, decidimos abrir las puertas de la revista a los nuevos temas y métodos que entonces circulaban por el mundo. En Francia, Italia, Estados Unidos y otros países emergió con fuerza el interés por la historia económica y social, apoyada en métodos cuantitativos, largas series de precios de productos agrícolas, salarios, comercio exterior, demografía, las alzas y bajas de la moneda, así como las transacciones de productos que podían estudiarse en la larga duración, como postuló Fernand Braudel. La historia de las mentalidades, que también se concentra en periodos dilatados, llevó a conocer procesos sociales, institucionales y humanos que resistían el cambio a lo largo de cientos de años.

La introducción de nuevas fuentes y métodos estadísticos y seriales, provocaron transformaciones profundas en el estudio de la producción agrícola, la minería, el comercio interior y exterior, el consumo, los flujos de capital y las maneras de vivir de las personas, transformaciones que obligaron al historiador a modificar sus formas de pensar, exponer y narrar sus temas de estudio. 
Poco a poco, además de publicar los artículos aprobados por el Consejo Editorial, comenzamos a solicitar y publicar trabajos dedicados a la historia económica y social. Para renovar las tareas del historiador quisimos saber cuál era la situación de las distintas ramas de la historia que se cultivaban entonces y sus perspectivas de desarrollo en el futuro próximo. Recibimos buenas respuestas.

En el número 82 de la revista presentamos una visión muy completa de los campos de mayor interés para los historiadores. El doctor Miguel León Portilla recogió las perspectivas de los estudios acerca del México prehispánico; Josefina Zoraida Vázquez analizó los trabajos dedicados a las síntesis de la historia mexicana; el maestro Luis González escribió sobre la microhistoria que él inauguró y su aplicación a un país tan contrastado que llamó Multiméxico; Alejandra Moreno Toscano analizó las diferencias entre el paisaje rural y el avance acelerado de los centros urbanos; Francisco Miranda examinó la problemática de los estudios acerca de la iglesia; Lorenzo Meyer analizó las perspectivas de la historia política; Woodrow Borah y Sherburne F. Cook resumieron las necesidades y perspectivas de la demografía histórica; Stanley J. Stein y Shane J. Hunt mostraron los pasos que seguía la historia económica en América Latina; y Eugenia Meyer y Alicia Olivera de Bonfil lograron un buen repaso del origen, métodos, desarrollo y perspectivas de la historia oral.

La última pregunta que nos solicita responder Rafael Rojas es sin duda la más difícil de darle buena respuesta. El cambio radical, veloz y global que ha producido el covid-19 en todos los aspectos de la vida contemporánea nos avisa que debemos prepararnos a escribir, comunicar y transmitir el conocimiento de manera diferente a nuestros hábitos anteriores. Ya tenemos un déficit para hacer llegar el conocimiento especializado a los grupos de niños y jóvenes que están en la última escala de la pobreza y la desigualdad. Pero los científicos y médicos, al unirse de un extremo a otro del mundo, lograron compartir conocimiento y 
equipos para apresurar la vacuna adecuada en un tiempo récord, a precios bajos para el consumidor, sin distinción de clases, partidos o creencias. Es decir, descubrieron medios formidables de comunicación, difusión y producción de medicamentos para el beneficio de toda la humanidad.

Cooperación y caminos semejantes de trabajo colectivo, participativo y humanitario debemos encontrar en las ciencias sociales y las humanidades. Sugiero que de las respuestas pertinentes que reciba el director de Historia Mexicana se haga una selección y luego un coloquio virtual para discutir las más apropiadas. 